\title{
Effect of Backbone Regiochemistry on Conductivity, Charge Density, and Polaron Structure of $\mathbf{n}$-Doped Donor-Acceptor Polymers
}

Wang, Suhao; Fazzi, Daniele; Puttisong, Yuttapoom; Jafari, Mohammad J.; Chen, Zhihua; Ederth, Thomas; Andreasen, Jens Wenzel; Chen, Weimin M.; Facchetti, Antonio; Fabiano, Simone

Published in:

Chemistry of Materials

Link to article, DOI:

10.1021/acs.chemmater.9b00558

Publication date:

2019

Document Version

Publisher's PDF, also known as Version of record

Link back to DTU Orbit

Citation (APA):

Wang, S., Fazzi, D., Puttisong, Y., Jafari, M. J., Chen, Z., Ederth, T., Andreasen, J. W., Chen, W. M., Facchetti, A., \& Fabiano, S. (2019). Effect of Backbone Regiochemistry on Conductivity, Charge Density, and Polaron Structure of n-Doped Donor-Acceptor Polymers. Chemistry of Materials, 31(9), 3395-3406.

https://doi.org/10.1021/acs.chemmater.9b00558

\section{General rights}

Copyright and moral rights for the publications made accessible in the public portal are retained by the authors and/or other copyright owners and it is a condition of accessing publications that users recognise and abide by the legal requirements associated with these rights.

- Users may download and print one copy of any publication from the public portal for the purpose of private study or research.

- You may not further distribute the material or use it for any profit-making activity or commercial gain

- You may freely distribute the URL identifying the publication in the public portal 


\section{Effect of Backbone Regiochemistry on Conductivity, Charge Density, and Polaron Structure of $\mathbf{n}$-Doped Donor-Acceptor Polymers}

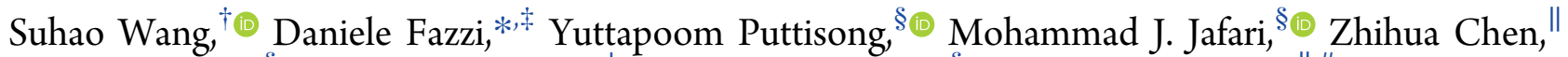
Thomas Ederth, ${ }^{\S}$ Jens W. Andreasen, ${ }^{\perp} \mathbb{\infty}$ Weimin M. Chen, ${ }^{\S}$ Antonio Facchetti, ${ }^{*}, \|, \#$ and Simone Fabiano* ${ }^{*}+\circ$

${ }^{\dagger}$ Laboratory of Organic Electronics, Department of Science and Technology, Linköping University, SE-60174 Norrköping, Sweden ${ }^{\ddagger}$ Institut für Physikalische Chemie, Department Chemie, Universität zu Köln, Luxemburger Str. 116, D-50939 Köln, Germany

${ }^{\S}$ Department of Physics Chemistry and Biology, Linköping University, SE-581 83 Linköping, Sweden

"Flexterra Corporation, 8025 Lamon Avenue, 60077-5318 Skokie, Illinois, United States

${ }^{\perp}$ Department of Energy Conversion and Storage, Technical University of Denmark, Frederiksborgvej 399, 4000 Roskilde, Denmark \# Department of Chemistry and the Materials Research Center, Northwestern University, 2145 Sheridan Road, Evanston, Illinois 60208 United States

\section{Supporting Information}

ABSTRACT: We investigated the influence of backbone regiochemistry on the conductivity, charge density, and polaron structure in the widely studied n-doped donor-acceptor polymer poly $\left[N, N^{\prime}\right.$-bis(2-octyldodecyl)-1,4,5,8-naphthalenediimide-2,6-diyl $]$-alt-5,5'-(2,2'-bithiophene) $\quad[\mathrm{P}$ (NDI2OD-T2)]. In contrast to classic semicrystalline polymers such as poly(3-hexylthiophene) (P3HT), the regioirregular (RI) structure of the naphthalenediimide (NDI)-bithiophene (T2) backbone does not alter the intramolecular steric demand of the chain versus the regioregular (RR) polymer, yielding RI-P(NDI2OD-T2) with similar energetics and optical features as its RR counterpart. By combining the electrical, UV-vis/infrared, X-ray diffraction, and electron paramagnetic

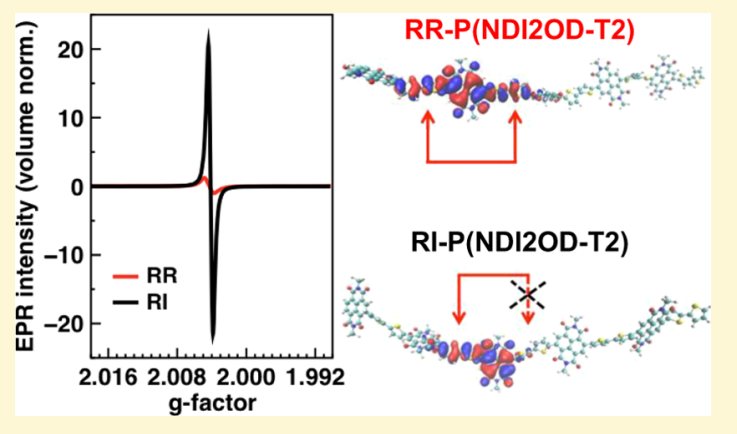
resonance data and density functional theory calculations, we quantitatively characterized the conductivity, aggregation, crystallinity, and charge density, and simulated the polaron structures, molecular vibrations, and spin density distribution of RR-/RI-P(NDI2OD-T2). Importantly, we observed that RI$\mathrm{P}(\mathrm{NDI} 2 \mathrm{OD}-\mathrm{T2})$ can be doped to a greater extent compared to its RR counterpart. This finding is remarkable and contrasts benchmark P3HT, allowing us to uniquely study the role of regiochemistry on the charge-transport properties of n-doped donor-acceptor polymers.

\section{INTRODUCTION}

Tuning the charge carrier density of $\pi$-conjugated polymers is a viable route to control their electronic and electrical properties. $^{1-3}$ Among several chemical strategies, this goal can be conveniently achieved either by blending a molecular dopant guest with the conjugated polymeric host via solution processing using a common organic solvent ${ }^{4-7}$ or by sequential doping upon exposure of the polymer film to the dopant vapors $^{8-10}$ or a dopant solution in an orthogonal solvent. ${ }^{11-13}$ The dopant molecules, having appropriate electronic properties, operate by removing electrons from the highest occupied molecular orbital (HOMO) level of the polymer for p-type doping or donating electrons to the lowest unoccupied molecular orbital (LUMO) level for n-type doping. ${ }^{14}$ The simplicity of forming a doped film on the substrate of interest and without the need of electrolyte/electrochemical apparatus is one of the intrinsic advantages of molecular doping over other doping strategies, such as the electrochemical one, facilitating implementation in optoelectronic devices. Moderately doped conjugated polymers have been used in several applications such as to minimize Ohmic losses in organic solar cells (OSCs), ${ }^{15,16}$ organic light-emitting diodes, ${ }^{17,18}$ and organic field-effect transistors (OFETs), ${ }^{19-21}$ whereas highly doped conducting polymers have found applications in numerous emerging energy-related technologies, such as unconventional batteries and organic thermoelectrics. ${ }^{22,23}$ Most of these technologies, however, require both efficient $\mathrm{p}$-doped (hole-transporting) and n-doped (electron-transporting) conducting polymers. Although p-doping of conjugated polymers is well established and yields materials with remarkably high electrical conductivity $(\sigma)$ values, ${ }^{24,25}$ the n-

Received: February 7, 2019

Revised: April 9, 2019

Published: April 11, 2019 


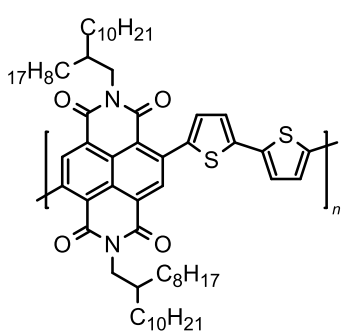

RR-P(NDI2OD-T2)

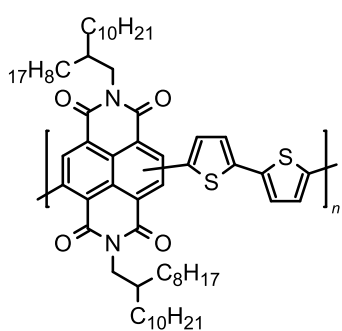

RI-P(NDI2OD-T2)

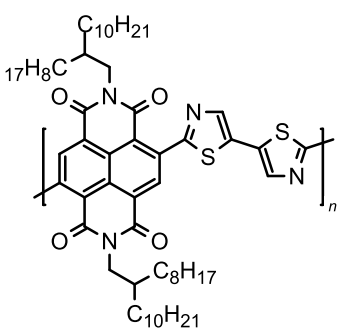

RR-P(NDI2OD-Tz2)

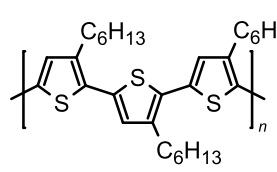

RR-P3HT

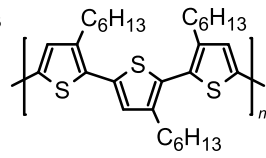

RI-P3HT

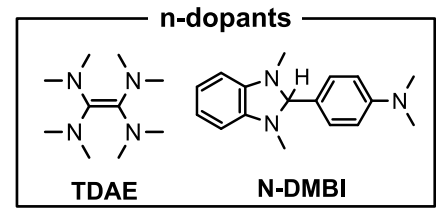

Figure 1. Chemical structures of typical donor-acceptor polymers such as RR-P(NDI2OD-T2), RI-P(NDI2OD-T2), RR-P(NDI2OD-Tz2), as well as homopolymers such as RR-P3HT and RI-P3HT. Chemical structures of typical n-dopants used in this study.

doping process and the resulting transport performance of $n$ doped semiconducting polymers remain far behind. ${ }^{26-31}$

The chemical and intrinsic electronic structure of the polymer has a critical impact on the charge transport and on the extent of the doping process. Thus, understanding the factors limiting the doping efficiency and charge transport in $n$ doped polymers is critical to guide the rational design of new high-conductivity conjugated polymers. With the exception of halo-substituted benzodifurandionephenylenvinylene polymers, which can reach $\sigma$ values as high as $0.6-14 \mathrm{~S} / \mathrm{cm}$ depending on the dopant, ${ }^{26,27}$ most $n$-doped polymers have electron conductivity lower than $0.01 \mathrm{~S} / \mathrm{cm}$. For example, it has been shown that regioregular (RR) poly $\left[N, N^{\prime}\right.$-bis $(2-$ octyldodecyl)-naphthalene-1,4,5,8-bis(dicarboximide)-2,6diyl]-alt-5,5'-(2,2'-bithiophene) [RR-P(NDI2OD-T2), Figure $1]$, a high field-effect/space-charge-limited electron mobility polymer extensively studied in the OFET/OSC literature, ${ }^{32}$ can reach a $\sigma$ value of only $\sim 0.003 \mathrm{~S} / \mathrm{cm}$ regardless of the dopant and processing conditions. In the pioneering work by Schlitz et al., RR-P(NDI2OD-T2) doped with dimethylbenzimidazoline (DMBI) derivatives yielded an optimized electrical conductivity of $\sim 0.001 \mathrm{~S} / \mathrm{cm}^{28}$ These low conductivity values were attributed to the limited solubility of the organic dopant in the host polymer matrix, limiting the doping efficiency to only $\sim 1 \%$. The introduction of polar side chains ${ }^{29,30}$ or "kinked" comonomers ${ }^{31}$ in naphthalene-based polymers enhances dopant/polymer miscibility resulting in a conductivity of $\sim 0.01-0.1 \mathrm{~S} / \mathrm{cm}$. Recently, we argued that the low electron conductivity observed for n-doped RR-P(NDI2ODT2) might be ascribed to the strong charge carrier intrachain localization, ${ }^{33}$ which is typical of donor-acceptor polymers. ${ }^{34-38}$ By replacing the donor bithiophene (T2) unit in RR-P(NDI2OD-T2) with the more electron-deficient bithiazole (Tz2) unit [i.e., RR-P(NDI2OD-Tz2), Figure 1], we were able to reduce the polymer donor-acceptor character as well as to enhance its electron affinity, resulting in a greater polymer dopability. ${ }^{39}$ In addition, because $\mathrm{Tz} 2$ has a far lower intrachain steric demand than $\mathrm{T} 2$, it planarizes the polymer backbone and thus enhances the intermolecular $\pi-\pi$ stacking interactions. Thus, RR-P(NDI2OD-Tz2) exhibited a higher $\sigma$ value (up to $\sim 0.1 \mathrm{~S} / \mathrm{cm}$ ) and enhanced thermoelectric response compared to RR-P(NDI2OD-T2). Despite this progress, the role of polymer backbone conformation, regiochemistry, and short-range (i.e., aggregation) character- istics on the doping efficiency remains unexplored and poorly understood. Note that ref 34 compares RR-P(NDI2OD-T2) to regioirregular (RI) perylenediimide-based polymers also having different donor units, which makes it difficult to decouple the effect of regiochemistry from that of the chemical structure/donor-acceptor character on charge density and conductivity.

Here, we investigate the influence of backbone regiochemistry on the electronic structure and charge transport of ndoped donor-acceptor P(NDI2OD-T2) polymers. In contrast to polythiophenes such as poly(3-hexylthiophene) (P3HT, Figure 1), the regioirregular backbone in RI-P(NDI2OD-T2) does not alter the intramolecular steric demand of the chain versus the RR polymer, allowing RI-P(NDI2OD-T2) to show similar energetics and optical features as its RR counterpart. Importantly, we observed that RI-P(NDI2OD-T2) can be doped to a far greater extent compared to RR-P(NDI2OD$\mathrm{T} 2$ ). These data are corroborated by complementary measurements such as electrical conductivity, electron paramagnetic resonance (EPR), UV-vis, and infrared (IR) spectroscopies, as well as by density functional theory (DFT) calculations. This results in striking contrasts to homopolymers such as P3HT, where the RI linkage leads to a low doping level, a reduced charge carrier mobility, and thus a low electrical conductivity. ${ }^{40}$ This allows us to uniquely study the role of regioregularity on the charge-transport properties of $\mathrm{n}$-doped donor-acceptor polymers.

\section{EXPERIMENTAL SECTION}

Polymer Samples. The RR-P(NDI2OD-T2) polymer was obtained from Flexterra Inc. $\left(M_{\mathrm{n}}=29.5 \mathrm{kDa}\right.$ and $\mathrm{P}=M_{\mathrm{w}} / M_{\mathrm{n}}=$ 2.1, ActivInk N2200). The RI-P(NDI2OD-T2) sample was synthesized according to the procedure reported in ref $44\left(M_{n}=\right.$ $35.0 \mathrm{kDa}$ and $\mathrm{B}=1.8)$, where a mixture of NDI2OD-2,6Br $\mathrm{Br}_{2}$ and NDI2OD-2,7Br $(77: 23 \mathrm{~mol} / \mathrm{mol})$ is reacted with $5,5^{\prime}$-bis(trimethylstannyl)-2,2'-dithiophene using $\mathrm{Pd}\left(\mathrm{PPh}_{3}\right)_{2} \mathrm{Cl}_{2}$ as the catalyst (Stille coupling, Figure S1). Note that this RI batch has a content of 2,6- and 2,7-NDI-T2 linkages in the backbone of $\sim 75$ and $25 \%$, respectively, as accessed by high-temperature $1 \mathrm{H}$ NMR spectroscopy (Figure S2). Considering the similarity of monomer steric/electronic characteristics, thus reactivity, the similarity between the monomer feed and incorporation molar ratios, and NMR assignment, the RI-P(NDI2OD-T2) sample should be randomized.

Film Preparation and Doping. All substrates were cleaned sequentially in water, acetone, and isopropanol for $10 \mathrm{~min}$ each and 

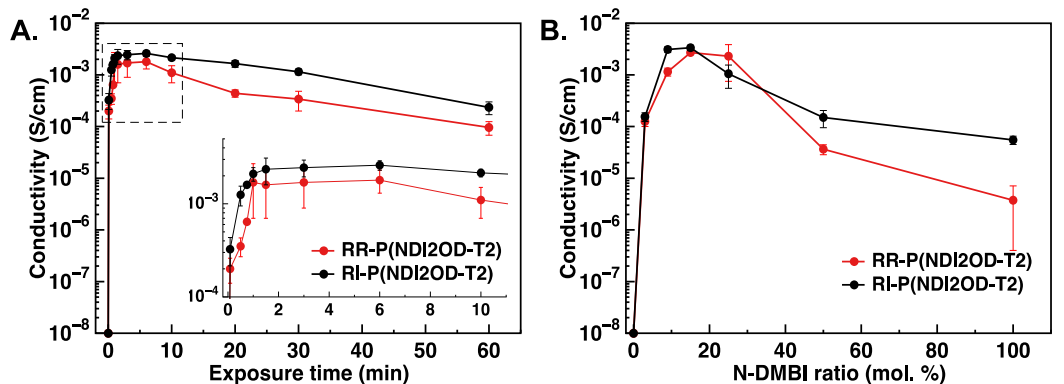

Figure 2. Electrical conductivity of RR- and RI-P(NDI2OD-T2) bulk films as a function of (A) TDAE exposure time and (B) N-DMBI molar ratio.

then dried by nitrogen blowing. RR-P(NDI2OD-T2) $(5 \mathrm{mg} / \mathrm{mL})$ and RI-P(NDI2OD-T2) (5 mg/mL) were obtained by dissolving the polymer in 1,2-dichlorobenzene under stirring at $70^{\circ} \mathrm{C}$ for at least $1 \mathrm{~h}$ to ensure complete dissolution of the polymers. The pristine films were obtained by spin-coating $5 \mathrm{mg} / \mathrm{mL}$ of $\mathrm{P}(\mathrm{NDI} 2 \mathrm{OD}-\mathrm{T} 2)$ at 1000 $\mathrm{rpm}$ for $30 \mathrm{~s}$. Then, the films were thermally annealed at $110^{\circ} \mathrm{C}$ under nitrogen atmosphere for $30 \mathrm{~min}$ and cooled down to room temperature naturally.

For tetrakis(dimethylamino)ethylene (TDAE) vapor doping, the polymer films, spin-coated on glass substrates, were exposed to the TDAE vapor inside a $20 \mathrm{~mL}$ airtight glass bottle filled with approximately $1 \mathrm{~mL}$ of $\mathrm{TDAE}$, following a procedure reported earlier. ${ }^{33}$ The exposure was stopped at the required time by removing the polymeric films from the TDAE bottle. For DMBI doping, $5 \mathrm{mg}$ / $\mathrm{mL}$ of RR-/RI-P(NDI2OD-T2) and $1.35 \mathrm{mg} / \mathrm{mL}$ of N-DMBI (Sigma-Aldrich) were separately dissolved in 1,2-dichlorobenzene. Then, the two abovementioned solutions were mixed in volume ratios. Prior to film deposition, the blend solutions were stirred and thermally annealed at $70{ }^{\circ} \mathrm{C}$ for at least $1 \mathrm{~h}$. After stirring, the solutions were spin-coated onto the glass substrates at $1000 \mathrm{rpm}$ for $30 \mathrm{~s}$. Then, the films were thermally annealed at $110{ }^{\circ} \mathrm{C}$ under nitrogen atmosphere for $30 \mathrm{~min}$ and cooled down to room temperature naturally.

Optical and Electrical Characterization. Optical absorption spectra were recorded using a UV-vis-NIR spectrophotometer (Varian, Cary-5000). All the electrical characteristics were measured using a Keithley 4200-SCS in a glove box under $\mathrm{N}_{2}$ atmosphere.

Reflection-absorption IR spectroscopy (RAIRS) was carried out at grazing angle $\left(86^{\circ}\right)$ reflection in a Bruker PMA 50 accessory, with a LN2-cooled mercury cadmium telluride detector, using a Bruker VERTEX 70 as the light source. A photoelastic modulator (Hinds: $\mathrm{ZnSe} 50 \mathrm{kHz}$ ) was used to modulate the polarization of the light, and demodulation of signals was accomplished with a lock-in amplifier (Stanford Research SR830). All spectra were acquired at $4 \mathrm{~cm}^{-1}$ resolution by 100 scans between 4000 and $800 \mathrm{~cm}^{-1}$.

For conductivity measurements, $\mathrm{Au}$ electrodes with a $\mathrm{Ti}$ adhesion layer $(L / W=30 \mu \mathrm{m} / 1000 \mu \mathrm{m})$ were deposited on the glass substrates prior to the deposition of the active layers. Electrical conductivity measurements were performed inside a $\mathrm{N}_{2}$-filled glove box using a semiconductor parameter analyzer (Keithley 4200-SCS). For top-gate bottom-contact OFETs fabrication, the dielectric polymer poly (methyl methacrylate) (PMMA) was dissolved in 2butanone to form a $70 \mathrm{mg} / \mathrm{mL}$ solution and then spin-coated on top of the pristine RR-/RI-P(NDI2OD-T2) films at $1500 \mathrm{rpm}$. The films were subsequently baked at $80{ }^{\circ} \mathrm{C}$ under a nitrogen atmosphere for 3 $\mathrm{h}$ and cooled down to room temperature. Finally, all the devices were completed by evaporating $\mathrm{Al}$ gate electrodes $(\sim 70 \mathrm{~nm})$ through a metal shadow mask on top of the dielectric layers.

EPR Measurements. EPR measurements were performed in a standard X-band Bruker ELEXSYS E500 spectrometer. The microwave power used in the experiment was kept below the signal saturation limit. All EPR spectra were obtained in dark at room temperature and are normalized to film detection volume.

Thin-Film Morphology Characterization. Atomic force microscopy (Digital Instruments) was performed in tapping mode using a silicon cantilever having a spring constant of $40 \mathrm{~N} / \mathrm{m}$. For the grazing incidence wide-angle X-ray scattering, the silicon substrate surface was aligned at a grazing incident angle of $0.18^{\circ}$ with respect to the incoming $\mathrm{X}$-ray beam, supplied by a rotating $\mathrm{Cu}$ anode operated at $50 \mathrm{kV}, 200 \mathrm{~mA}$ in point focus mode. ${ }^{41}$ The $\mathrm{Cu} \mathrm{K} \alpha$ radiation [wavelength $(\lambda)=1.542 \AA$ ] was collimated and monochromatized with a one-dimensional multilayer optic. The scattered radiation was recorded in vacuum on photostimulable imaging plates $121.5 \mathrm{~mm}$ from the sample. The data integration and conversion to reciprocal space coordinates was done with MATLAB scripts. ${ }^{42}$

Computational Methods. $\mathrm{P}(\mathrm{NDI} 2 \mathrm{OD}-\mathrm{T} 2)$ was modeled via an oligomer approach at the DFT level, using the functional $\omega$ B97X-D and the basis set 6-311G*. Neutral and charged (i.e., radical anion) species were described at the restricted and unrestricted DFT (UDFT) level of theory, respectively. The stability of the DFT solution was checked for each case by applying a broken symmetry (BS) approach. No instability was found for the neutral species of each oligomer, confirming that the restricted DFT treatment is appropriate for such cases. For the charged species of RI-P(NDI2OD$\mathrm{T} 2)$, that is for the oligomer featuring at least five repeat units $(n=5)$, an instability was found. The stabilization energy is given by the energy difference $\Delta E=E_{\mathrm{UDFT}-\mathrm{BS}}-E_{\mathrm{UDFT}}$. All structures, namely RRand RI-P(NDI2OD-T2) $(n=1,5)$, were optimized in the neutral and charged states (using their most stable solution of the ground-state wave function). For each oligomer and for each electronic state (i.e., neutral and charged), the IR spectra were computed, and the vertical electronic transitions were evaluated at the time-dependent (TD) DFT level. IR calculations were computed as well. All calculations were performed using Gaussian $16 .^{43}$

\section{RESULTS AND DISCUSSION}

Polymer Sample Preparation and Doping Procedure. RR- and RI-P(NDI2OD-T2) were synthesized following a procedure previously reported. ${ }^{44}$ The LUMO energies of RRand RI-P(NDI2OD-T2) are nearly invariant $(\approx-3.95 \mathrm{eV})$ despite the different regiochemistry. ${ }^{44}$ This datum is not surprising because in this donor-acceptor polymer, the LUMO is predominantly localized on the NDI unit, while the HOMO delocalizes between the NDI and the T2 units. $^{45,46}$ In stark contrast, the backbone regiochemistry is known to greatly influence the molecular orbital energetics of polythiophenes such as $\mathrm{P} 3 \mathrm{HT}$, with the HOMO energy level varying by $\sim 0.4 \mathrm{eV}(\sim-4.30 \mathrm{eV}$ for RR-P3HT and $\sim-4.70 \mathrm{eV}$ for RI-P3HT). ${ }^{47}$ In addition, the NDI-based polymer samples used in this study have comparable number-average molecular weights and polydispersity indexes: $M_{\mathrm{n}}=35.0 \mathrm{~kg} / \mathrm{mol}, \mathrm{D}=1.8$ for RI-P(NDI2OD-T2), and $M_{\mathrm{n}}=29.5 \mathrm{~kg} / \mathrm{mol}, D=2.1$ for RR-P(NDI2OD-T2). As both RR- and RI-P(NDI2OD-T2) have similar electron affinities and molecular weights, we conclude that the difference in electrical conductivity and charge density observed for the two doped polymers is due to different energetics and degree of polymerization (vide infra). 
Table 1. Summary of Polymer Characterization Data and Electrical Measurements

\begin{tabular}{|c|c|c|c|c|c|c|c|c|}
\hline \multirow[b]{2}{*}{$\mathrm{P}(\mathrm{NDI} 2 \mathrm{OD}-\mathrm{T} 2)$} & \multirow[b]{2}{*}{$M_{\mathrm{n}}(\mathrm{kg} / \mathrm{mol})$} & \multirow[b]{2}{*}{ D } & \multirow[b]{2}{*}{$E_{\mathrm{g}}^{\mathrm{Opt}}(\mathrm{eV})$} & \multirow[b]{2}{*}{ LUMO (eV) } & \multicolumn{2}{|c|}{$\sigma_{\text {avg }}(\mathrm{S} / \mathrm{cm})$} & \multirow[b]{2}{*}{$\mu_{\text {avg }}\left(\mathrm{cm}^{2} / \mathrm{V} \mathrm{s}\right)$} & \multirow[b]{2}{*}{$n\left(\times 10^{17} \mathrm{~cm}^{-3}\right)$} \\
\hline & & & & & TDAE & N-DMBI & & \\
\hline $\mathrm{RR}$ & 29.5 & 2.1 & 1.43 & -3.95 & 0.0018 & 0.0027 & 0.13 & 2.0 \\
\hline RI & 35.0 & 1.8 & 1.53 & -3.96 & 0.0026 & 0.0033 & 0.02 & 9.4 \\
\hline
\end{tabular}

TDAE was used as the n-type dopant, unless specified otherwise. TDAE has a strong reducing character with an oxidation potential $(\approx-0.6 \mathrm{~V}$ vs SCE$)$ that is comparable to the reduction potential of both RR- and RI-P(NDI2OD-T2) $(\sim-0.5 \mathrm{~V}$ vs SCE $) .^{48}$ Hence, the doping process occurs through an electron transfer from the dopant to the semiconducting polymer. The polymer films were exposed to the TDAE vapor inside a nitrogen-filled glove box (more details of the device preparation and doping procedure are reported in the Experimental Section).

Electrical Measurements. The electrical properties of both RR- and RI-P(NDI2OD-T2) films were investigated before and after exposure to the TDAE vapors in an inert environment. The conductivity data are summarized in Figure $2 \mathrm{a}$ as a function of the exposure time. Before exposure, both $\mathrm{RR}$ - and RI-P(NDI2OD-T2) are in their undoped pristine state and show $\sigma$ values as low as $\sim 10^{-8} \mathrm{~S} / \mathrm{cm}$. After exposure to the dopant vapors (after just $60 \mathrm{~s}$ of exposure, at room temperature), the $\sigma$ of both polymers steeply increases, reaching a maximum value of $\sim 1.8( \pm 0.5) \times 10^{-3}$ and $\sim 2.6$ $( \pm 0.3) \times 10^{-3} \mathrm{~S} / \mathrm{cm}$ for RR- and RI-P(NDI2OD-T2), respectively. These values are almost 5 orders of magnitude higher than those of the pristine polymer films. The conductivity of both polymers eventually decreases for longer exposure times. The maximum $\sigma$ values and trends are in agreement with previous reports for RR-P(NDI2OD-T2), ${ }^{33,39}$ assuring that the films investigated in this study are representative of the high-performance polymer samples. Note also that these $\sigma$ values are independent of the nature of the dopant because the molecular dopant 4-(1,3-dimethyl2,3-dihydro- $1 H$-benzoimidazol-2-yl)- $N, N$-dimethylaniline (NDMBI) affords comparable results (Figure 2b). Benzimidazole derivatives such as N-DMBI are air-stable base dopants that allow for $\mathrm{n}$-doping of organic semiconductors through hydride $\left(\mathrm{H}^{-}\right)$transfer. $^{49}$ As shown in Figure $2 \mathrm{~b}$, the conductivity of both N-DMBI-doped RR- and RI-P(NDI2OD-T2) rapidly increases by 5 orders of magnitude and saturates to $\sim 2.7$ $( \pm 0.3) \times 10^{-3} \mathrm{~S} / \mathrm{cm}$ for RR-P(NDI2OD-T2) at an N-DMBI molar ratio of $15 \mathrm{~mol} \%$ (maximum conductivity not greater than $\left.\sim 5 \times 10^{-3} \mathrm{~S} / \mathrm{cm}\right)$ and $\sim 3.3( \pm 0.4) \times 10^{-3} \mathrm{~S} / \mathrm{cm}$ for RI$\mathrm{P}(\mathrm{NDI} 2 \mathrm{OD}-\mathrm{T} 2)$ (maximum conductivity not greater than $\sim 5$ $\times 10^{-3} \mathrm{~S} / \mathrm{cm}$ ) at an N-DMBI molar ratio of $9 \mathrm{~mol} \%$. For dopant molar ratio larger than $25 \mathrm{~mol} \%$ for RR-P(NDI2OD$\mathrm{T} 2$ ) and $15 \mathrm{~mol} \%$ for RI-P(NDI2OD-T2), the conductivity of both samples starts to decrease. These values are comparable to those of TDAE-doped samples and consistent with previous reports. $^{28}$ When compared to doped RR and regiorandom $\mathrm{P} 3 \mathrm{HT}$, charge transport in doped $\mathrm{P}(\mathrm{NDI} 2 \mathrm{OD}-\mathrm{T} 2)$ appears to be more tolerant to the regiochemistry. Indeed, the $\sigma$ of doped RR-P3HT $\left(\sigma_{\max } \approx 10 \mathrm{~S} / \mathrm{cm}\right)$ is orders of magnitude higher than that of the regiorandom counterpart $\left(\sigma_{\max } \approx 0.01 \mathrm{~S} /\right.$ $\mathrm{cm}) .{ }^{40}$ It is also noteworthy that for P(NDI2OD-T2), two different doping processes lead to maximum electrical conductivity similar for all doped samples. In addition, similar conductivity values have been reported for RR-P(NDI2ODT2) doped with dimer dopants reacting quantitatively by electron transfer. ${ }^{50}$ Thus, we believe that the electrical conductivity saturation observed in Figure 2 for both RRand RI-P(NDI2OD-T2) is not due to inefficiencies of the dopant but rather linked to intrinsic limitations of the polymer, as also suggested recently. ${ }^{39}$

To identify any correlations between conductivity of the doped films and mobility of the pristine polymers, we tested the electron-transport properties of pristine RR- and RI$\mathrm{P}(\mathrm{NDI} 2 \mathrm{OD}-\mathrm{T} 2)$ polymers by field-effect mobility measurements. Top-gate bottom-contact OFETs were fabricated using PMMA as the gate insulator. First, the semiconductor thin films were spin-coated on untreated gold source-drain electrodes/glass substrates from solution $(5 \mathrm{mg} / \mathrm{mL}$ in 1,2 dichlorobenzene). The films were then thermally annealed at $110{ }^{\circ} \mathrm{C}$ under nitrogen atmosphere for $30 \mathrm{~min}$ and cooled down to room temperature. Next, the polymeric dielectric PMMA layer $(70 \mathrm{mg} / \mathrm{mL}$ in 2-butanone) was spin-coated. These films were annealed at $80{ }^{\circ} \mathrm{C}$ prior to thermal evaporation of the aluminum gate electrode (further details about OFET fabrication and characterizations are reported in the Experimental Section). The transfer characteristics of these OFETs are reported in the Supporting Information (Figure S3), and the saturation mobility $(\mu)$ values are summarized in Table 1. RR- and RI-P(NDI2OD-T2) show a rather moderate difference in mobility $\left[\mu_{\mathrm{RR}} / \mu_{\mathrm{RI}}=\sim 6\right]$, with RI-P(NDI2ODT2) having an average $\mu_{\mathrm{RI}}=0.020 \mathrm{~cm}^{2} / \mathrm{V} \mathrm{s}$, which is only 6 times lower than that of RR-P(NDI2OD-T2) $\left(\mu_{\mathrm{RR}}=0.13\right.$ $\left.\mathrm{cm}^{2} / \mathrm{V} \mathrm{s}\right)$. This transport trend is in agreement with recent mobility values measured for these polymers by space-chargelimited currents measurements in unipolar diodes ${ }^{44}$ and for other NDI-based polymers in OFETs. ${ }^{51}$ Very notably, RI$\mathrm{P}(\mathrm{NDI} 2 \mathrm{OD}-\mathrm{T} 2)$ shows a remarkably high charge carrier mobility compared with other RI polymers such as $\mathrm{P} 3 \mathrm{HT}$ $\left(\mu_{\mathrm{RR}} / \mu_{\mathrm{RI}}=\sim 1000\right),{ }^{52}$ pyridal $[2,1,3]$ thiadiazole-based polymers $\left(\mu_{\mathrm{RR}} / \mu_{\mathrm{RI}}=\sim 120\right),{ }^{53}$ and poly(dithienyl-benzo[1,2-b:4,5$\left.b^{\prime}\right]$ dithiophene-co-5-fluoro-2,1,3-benzothiadiazole $)\left(\mu_{\mathrm{RR}} / \mu_{\mathrm{RI}}=\right.$ 70). ${ }^{54}$ Qualitatively, by assuming the field-effect mobility $\left(\mu_{\mathrm{FET}}\right)$ as an estimation for the electron mobility in our doped films, ${ }^{28}$ we estimate the maximum carrier concentration in our RI-P(NDI2OD-T2) films $\left(\sim 9.4 \times 10^{17} \mathrm{~cm}^{-3}\right)$ to be about 5fold that of RR-P(NDI2OD-T2) $\left(\sim 2.0 \times 10^{17} \mathrm{~cm}^{-3}\right)$, taking into account that $\sigma=n e \mu_{\mathrm{FET}}$, where $e$ is the fundamental charge. We also attempted to measure the mobility of the doped films, up to doping levels where this measurement could be meaningful, observing that, even for low doping levels, the charge density in RI-P(NDI2OD-T2) is larger $(\sim 2 \times)$ than that of RR-P(NDI2OD-T2) (see Figure S4 for further details).

Optical Absorption Spectroscopy. To monitor the changes in the electronic structure of the polymer upon doping, UV-vis-NIR spectroscopy was performed on thin polymer films for different TDAE exposure times. Figure 3 shows the absorption spectra of both RR- and RI-P(NDI2OD$\mathrm{T} 2)$ films before and after exposure $(15 \mathrm{~h})$ to the TDAE vapor. Similar to literature reports, ${ }^{55}$ undoped RR-P(NDI2OD-T2) shows an intense absorption band at $\sim 390 \mathrm{~nm}$, which is assigned to a high-energy $\pi-\pi^{*}$ transition and a broad 


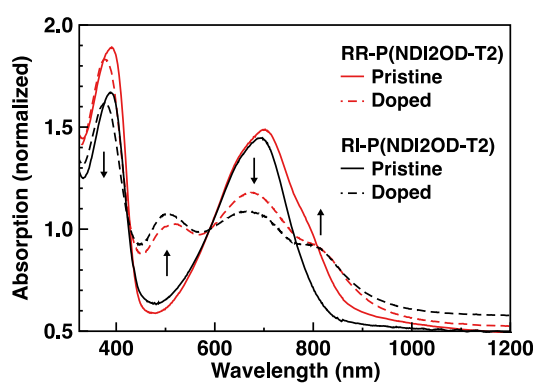

Figure 3. Normalized UV-visible absorption spectra of RR- and RI$\mathrm{P}(\mathrm{NDI} 2 \mathrm{OD}-\mathrm{T} 2)$ thin films before and after TDAE exposure. The new peaks at 500 and $805 \mathrm{~nm}$ appear after TDAE exposure for $15 \mathrm{~h}$, indicating the formation of polaronic species.

structured low-energy band centered at $\sim 705 \mathrm{~nm}$. This latter band results from an intramolecular charge-transfer (CT) transition between the NDI and the bithiophene units (705 $\mathrm{nm})$ and from an intermolecular transition $(\sim 800 \mathrm{~nm})$ between chain segments, representing a spectroscopic fingerprint of the formation of aggregate species ( $30 \%$ aggregate content). ${ }^{55}$ In contrast, undoped RI-P(NDI2OD-T2) films exhibit a less structured CT absorption band $(\sim 700 \mathrm{~nm})$ and a less intense $800 \mathrm{~nm}$ band, indicative of reduced aggregation. This is in agreement with previous observations and shows that, despite significant structural modification of the polymer backbone, RI-P(NDI2OD-T2) films retain a substantial fraction of aggregates. ${ }^{44}$ TDAE treatment of both RR- and RI-P(NDI2OD-T2) films decreases the band intensity at $\sim 390$ and $\sim 700 / 705 \mathrm{~nm}$, together with the appearance of two new absorption bands at $\sim 500$ and $\sim 820 \mathrm{~nm}$. Note that TDAE absorbs at 205 and $273 \mathrm{~nm}$ in the UV spectrum. ${ }^{56}$ In addition, the bands at $\sim 390$ and $\sim 700 / 705 \mathrm{~nm}$ shift to shorter wavelengths as the n-doping level increases (Figures 3 and S5). These optical spectra are consistent with the formation of negative polarons, as also recently supported by TDDFT calculations. $^{33}$

Film Microstructure and Molecular Packing. Grazingincidence wide-angle X-ray scattering (GIWAXS) of spincoated thin films allows us to investigate the impact of TDAE doping on the solid-state microstructure of RR- and RIP(NDI2OD-T2) (Figures 4 and S6 and Table 2). For both pristine and doped RR-P(NDI2OD-T2), the majority of the crystalline regions have a $\pi$-face-on orientation of the polymer chains. GIWAXS diffractograms (Figure 4) indicate that the $\pi$ stacking distance of neat RR-P(NDI2OD-T2) shifts from $d_{010}$ $=4.0$ (undoped) to 3.5-3.8 $\AA$ upon doping (Figure 4 and Table 2). The lamellar stacking of neat RR-P(NDI2OD-T2) is oriented in-plane and the distance also decreases from $d_{100}=$ 25.5 (undoped) to $25.1-24.4 \AA$ in the doped samples. This behavior is consistent with previous literature for doped RR$\mathrm{P}(\mathrm{NDI} 2 \mathrm{OD}-\mathrm{T} 2)^{34}$ and suggests that optimal doping $(3 \mathrm{~min})$ densifies crystalline aggregates likely via planarization of the $\pi$ conjugated backbone. ${ }^{39}$ Relative crystallinity of the RR$\mathrm{P}($ NDI2OD-T2) samples for the 001/010 crystal directions, as evaluated by the integrated reflection intensities, generally increases for optimal doping time $[1.5 / 1.0 \rightarrow 3.3 / 2.4]$, whereas crystallite dimensions are far less affected. Further doping strongly depresses 001 crystallinity, whereas along the 010 direction, it remains close to the weekly doped sample. Similarly, the RI-P(NDI2OD-T2) polymer exhibits preferential face-on $\pi$-stacking of the crystalline domains with the $d_{010}$ and $d_{100}$ periodicities exhibiting a far less dependence upon doping
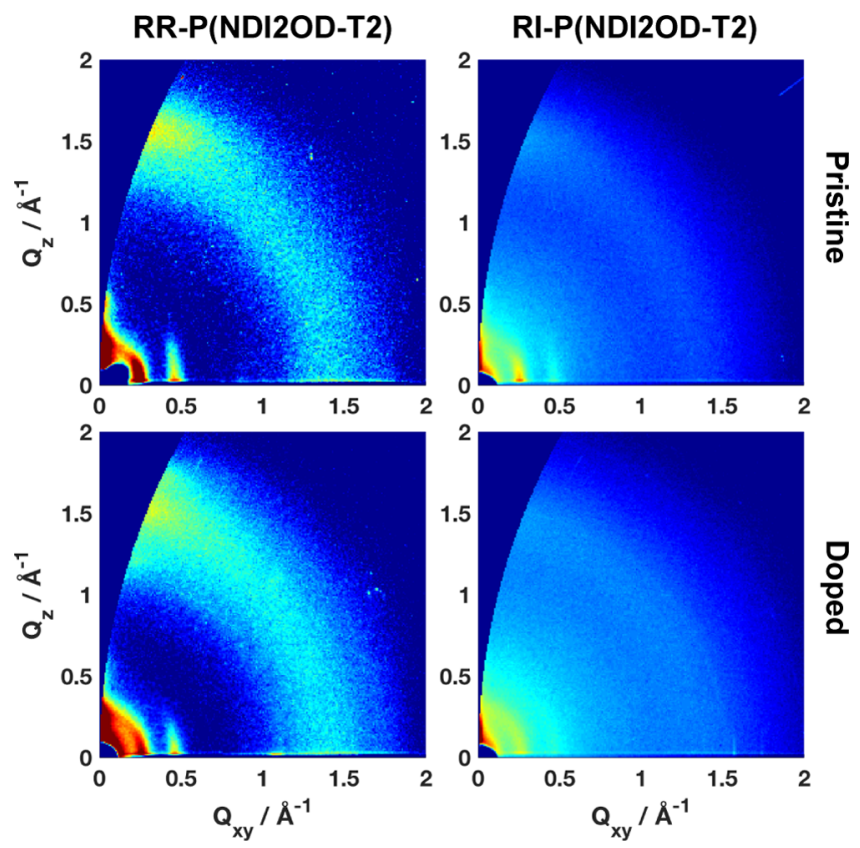

Figure 4. GIWAXS two-dimensional scattering patterns of RR- and RI-P(NDI2OD-T2) before and after overnight (15 h) exposure to TDAE vapor.

and remaining in a close range of 3.8-3.6 and 24.0-22.7 $\AA$, respectively. Both the relative crystallinity and the coherence length of the doped RI-P(NDI2OD-T2) samples are far lower than those of the RR counterpart and generally less affected or slightly enhanced for a short doping period. Thus, overall, RR$\mathrm{P}$ (NDI2OD-T2) adopts a substantially more ordered structure than the RI one, but both polymers exhibit, after doping, similar stacking/lamellar geometrical parameters.

EPR Analysis. To shed light on the origin of the unprecedented enhanced conductivity of the RI polymer, TDAE-doped RR- and RI-P(NDI2OD-T2) films were investigated via EPR. EPR allows for a direct observation of the radical anions formed upon electron transfer and were performed at room temperature in an oxygen-free environment. The results are reported in Figure 6. Both pristine RRand RI-P(NDI2OD-T2) films do not exhibit any EPR signals. However, TDAE-doped RR- and RI-P(NDI2OD-T2) show the presence of paramagnetic species with a characteristic electron $g$-factor of about 2.0041 and 2.0040, respectively (Figure 5a). These values are slightly larger than that of a free electron $(g=2.0023)$ but within the range commonly reported for organic radicals. ${ }^{57}$ Remarkably, the EPR spectra indicate that doped RI-P(NDI2OD-T2) possesses a significantly larger amount (up to four times) of paramagnetic species than doped RR-P(NDI2OD-T2), supporting the observation that higher charge carrier density is attained in doped RI-P(NDI2OD-T2) than RR-P(NDI2OD-T2) films. Note that a similar trend is observed when N-DMBI is used as the $n$-dopant (Figure S7). This observation is in stark contrast to p-doping of P3HT with different regioregularity, where RR-P3HT was reported to possess a significantly larger amount of paramagnetic species compared to RI-P3HT. ${ }^{58}$ In addition to this observation, the EPR signal of the doped RI-P(NDI2OD-T2) exhibits a spectral line width of $0.15 \mathrm{mT}$, whereas for doped RR$\mathrm{P}(\mathrm{NDI} 2 \mathrm{OD}-\mathrm{T} 2)$, the line width becomes broader with a spectral line width of $0.30 \mathrm{mT}$ (Figures $5 \mathrm{~b}$ and S8). The narrowing of the EPR line width is consistent with a higher 
Table 2. GIWAXS Quantitative Data Analysis

\begin{tabular}{|c|c|c|c|c|c|c|c|}
\hline \multirow[b]{2}{*}{$\mathrm{P}(\mathrm{NDI} 2 \mathrm{OD}-\mathrm{T} 2)$} & \multirow[b]{2}{*}{ doping time } & \multicolumn{3}{|c|}{$(100)$} & \multicolumn{3}{|c|}{$(010)$} \\
\hline & & $\overline{d \text {-spacing }[\AA]}$ & relative crystallinity $[\AA]$ & coherence length $[\AA]$ & $\overline{d \text {-spacing }[\AA]}$ & relative crystallinity $[\AA]$ & coherence length $[\AA]$ \\
\hline \multirow[t]{3}{*}{ RR } & none & 25.5 & 1.5 & 151 & 4.0 & 1.0 & 17 \\
\hline & $3 \mathrm{~min}$ & 25.1 & 3.3 & 156 & 3.5 & 2.4 & 11 \\
\hline & $15 \mathrm{~h}$ & 24.4 & 0.4 & 108 & 3.8 & 2.9 & 12 \\
\hline \multirow[t]{3}{*}{$\mathrm{RI}$} & none & 24.5 & 0.3 & 104 & 3.6 & 0.5 & 10 \\
\hline & $3 \mathrm{~min}$ & 24.7 & 0.4 & 111 & 3.7 & 0.7 & 10 \\
\hline & $15 \mathrm{~h}$ & 24.0 & 0.1 & 71 & 3.8 & 0.3 & 10 \\
\hline
\end{tabular}
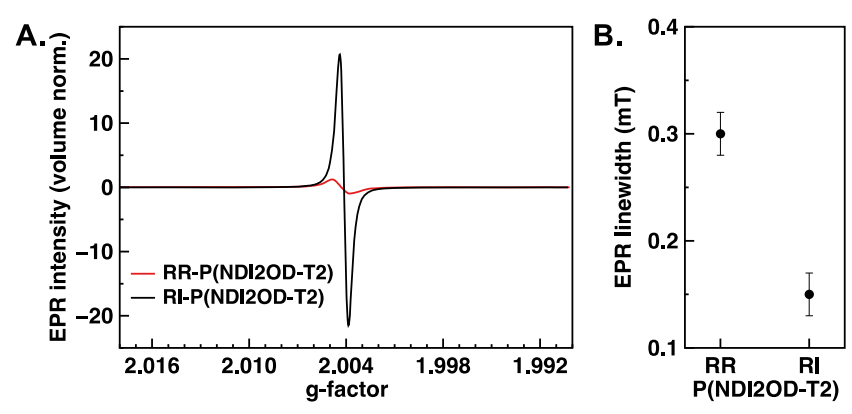

Figure 5. (A) EPR spectra of doped RR- and RI-P(NDI2OD-T2) films (TDAE exposure for $15 \mathrm{~h}$ ), indicating that doped RI$\mathrm{P}(\mathrm{NDI} 2 \mathrm{OD}-\mathrm{T} 2)$ possesses a significantly larger amount of paramagnetic species than RR-P(NDI2OD-T2) under the same doping conditions. (B) Corresponding EPR line widths.

doping level for RI-P(NDI2OD-T2) as compared to the RR counterpart. ${ }^{59}$

DFT Calculations. We performed extensive DFT calculations for both the neutral and charged species to get insights into the molecular and electronic structures describing the pristine and doped RR- and RI-P(NDI2OD-T2), respectively, and thus rationalize the experimental observations. RR and $\mathrm{RI}$ polymers are modeled considering the NDI2OD-T2 linkage at the NDI 2,6-(meta-) and 2,7-(para-) positions. RR-P(NDI2OD-T2) shows the linkage between the NDI2OD and $\mathrm{T} 2$ units in 2,7-(para) position, whereas RI-P(NDI2OD-T2) shows a mixture of both 2,6-(meta) and 2,7-(para) positions. For each case, we investigated the NDI2OD-T2 repeat unit (here called $n_{1}$, Figure 6) and up to a five-member oligomer

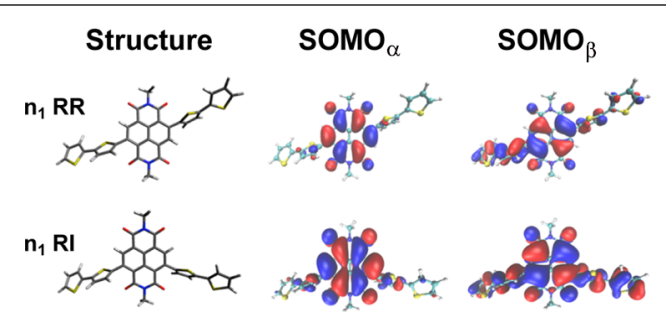

Figure 6. Molecular structure and SOMO of the charged (i.e., anionic) species for RR and RI monomers $(n=1)$. Calculations are at the U $\omega \mathrm{B} 97 \mathrm{X}-\mathrm{D} / 6-311 \mathrm{G}^{*}$ level of theory.

$\left(n_{5}\right.$, Figure 7$)$, the latter as a representative of the polymer limit. A first attempt to explore whether the EPR signal correlates with the polymer regiochemistry consisted in analyzing the molecular property variation induced by the RR- and the RI-substitution. As already documented by Neher et $\mathrm{al}^{44}$ and Gierschner at al., ${ }^{60}$ the electronic structure of RRand RI-P(NDI2OD-T2) is quite similar despite the different ground-state cross-conjugation via the meta connection. This

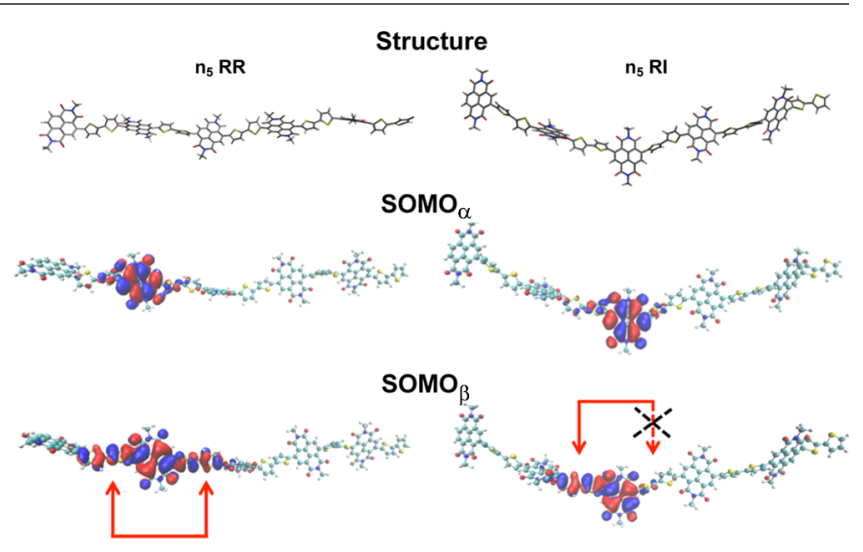

Figure 7. Equilibrium molecular structures and SOMOs of the charged (i.e., anionic) species for RR and RI oligomers $(n=5)$. Calculations are at the U $\omega$ B97X-D/6-311G* level for the RR and at the BS-U $\omega$ B97X-D/6-311G* level for the RI.

result was rationalized by the fact that the meta linkage does not alter the intramolecular steric demand of the polymer backbone versus the para substitution, allowing RI-P(NDI2OD-T2) to display similar electronic properties, such as electronic transitions and HOMO-LUMO gap, as its RR counterpart.

Starting from these observations, we tackled the problem from a different perspective that is more related to the polaronic properties. Thus, we analyzed the single occupied molecular orbital (SOMO) distributions and the spin density of the negatively charged species. As reported in Figure 6, the meta or para substitutions in the NDI2OD-T2 unit do not cause any perturbation or asymmetric distribution into the spatial extension of the SOMO. For both $n_{1}$-RR and $n_{1}$-RI, $\mathrm{SOMO}_{\alpha}$ and $\mathrm{SOMO}_{\beta}$ are symmetric with respect to the local $D_{2 h}$ point group of the NDIO2D unit and thus cannot provide any a priori chemical reason which would justify a different spin density for the two species, as instead experimentally observed. However, a monomer (or a short-length oligomer) cannot be a representative for the polymer properties.

Exploring the polymer limit, we computed the structural and electronic properties of long oligomers, up to five-member units $\left(n_{5}\right)$, for both the neutral and the charged (i.e. anionic) electronic states. Dealing with extended $\pi$-conjugated systems, and based on our previous experience in investigating the electronic properties of another high electron mobility organic polymer (namely BBL), ${ }^{33}$ we carefully checked the stability of the computed UDFT-pseudo-wave function, through the BS formalism. $^{61,62}$ In fact, the UDFT solution might become unstable by increasing the extension of the $\pi$-conjugated core, thus being incapable of describing the properties of charged (or excited) states properly. ${ }^{63}$ We already demonstrated how, by increasing the oligomer lengths - as for the case of BBL- 

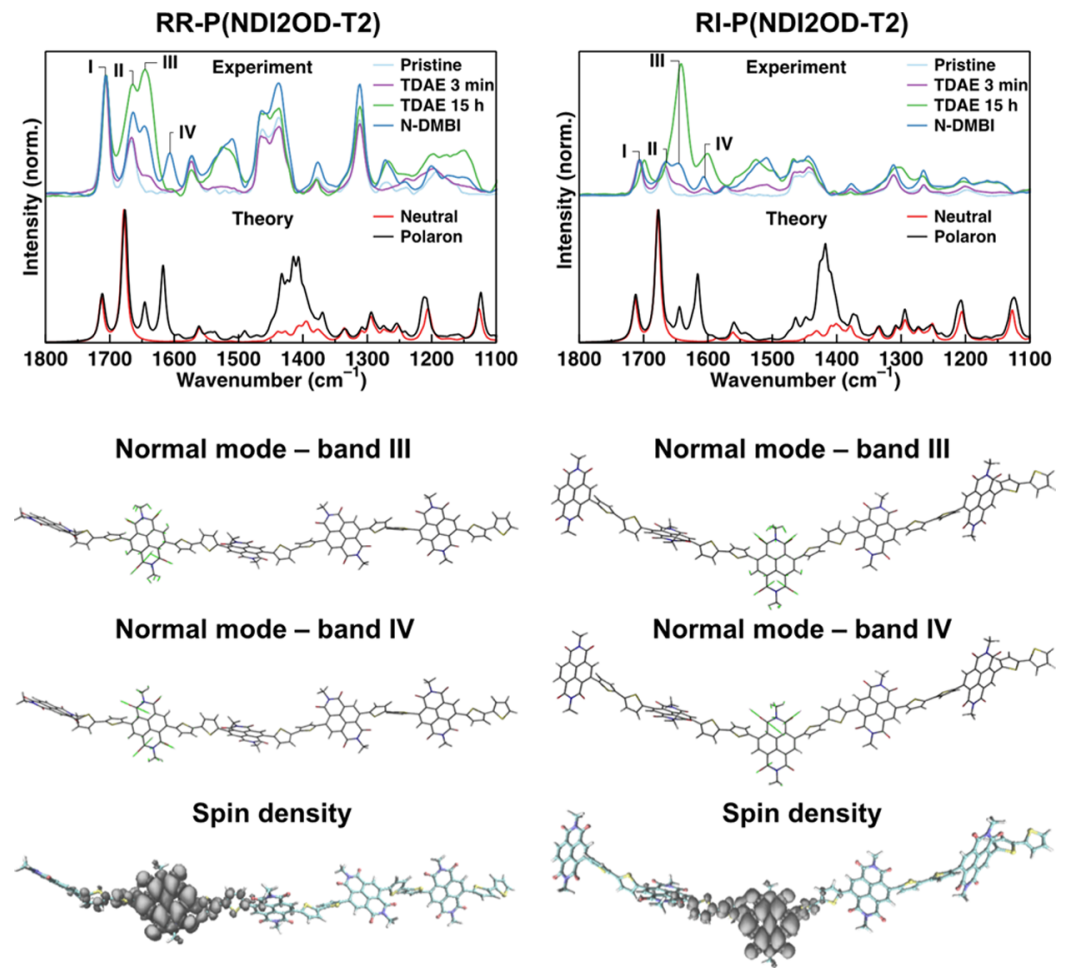

Figure 8. Comparison between experimental RAIRS spectra and the theoretical calculations for the RR (left panel) and RI (right panel) species. RAIRS were recorded for the pristine species (cyan), after $3 \mathrm{~min}$ and $15 \mathrm{~h}$ of doping with TDAE (purple and green) and doping with DMBI (blue). DFT IR calculated spectra (scaling factor 0.95) are reported for the neutral species $\left(\omega \mathrm{B} 97 \mathrm{X}-\mathrm{D} / 6-311 \mathrm{G}^{*}\right.$, red) and for the negatively charged species (U $\omega$ B97X-D/6-311G*, black). The IR spectrum of the charged RI-P(NDI2OD-T2) was computed with UDFT BS calculations. Sketches of the normal modes III and IV (displacements are indicated via green arrows) and spin density for the polaronic species (isosurfaces $0.0001 \AA^{3}$, gray for both $\alpha$ and $\beta$ ) are reported.

the UDFT-BS solution become more stable than the UDFT one, leading to different electronic structures (e.g., electronictransition energies or spin density distribution). ${ }^{33}$ Thus, $n_{5}$ RR$\mathrm{P}$ (NDI2OD-T2) does not show any instability of the charged state UDFT wave function. However, the UDFT wave function of $n_{5}$ RI-P(NDI2OD-T2) is unstable, leading to a more stable UDFT BS solution. The stabilization energy, evaluated as $\Delta E=E_{\mathrm{UDFT}-\mathrm{BS}}-E_{\mathrm{UDFT}}$, is $-0.22 \mathrm{eV}$. This is a remarkable result because it indicates that in a more extended $\pi$-conjugated system, the meta substitution (or the RI structure, as named here) does affect the description of the electronic structure of the charged (i.e., polaronic) species, requiring an unrestricted BS approach (UDFT-BS), rather than UDFT. In practical terms, in analogy to biradicaloid systems, ${ }^{64,65}$ this case can be related to a multiconfigurational character of the wave function. A fully satisfactory description of the charged (polaron) electronic structure in RI$\mathrm{P}$ (NDI2OD-T2) would require multiconfigurational wave function methods or hybrid approaches (e.g., multiconfigurational pair-DFT), still nonpractical for such extended systems with the current state-of-the art computational resources. ${ }^{66}$

With enhanced accurate description of the ground state of the charged electronic structure (within the UDFT framework), we can now analyze the differences between RR- and RI-P(NDI2OD-T2). As reported in Figure 7, the equilibrium molecular structures of charged RR- and RI-chains differ, being the first linear and the latter distorted, with a kinked structure as induced by the meta substitution. The different single-chain structures also reflect, on a large scale, different packing and order/disorder film morphologies (as discussed in the
GIWAXS section and commented in the following RAIRS section). Analyzing the electronic structure of charged species and their molecular orbitals, $\mathrm{SOMO}_{\alpha}$ and $\mathrm{SOMO}_{\beta}$ of the two species differ, with the RR-structure maintaining the local $D_{2 h}$ symmetry distribution of the molecular orbitals while the RIdoes not. In particular, the $\mathrm{SOMO}_{\beta}$ of the RI-P(NDI2OD-T2) presents an asymmetric distribution with respect to the NDI2OD unit. This asymmetric distribution leads to a spin density distribution which is asymmetric too, being unbalanced toward one bithiophene unit rather than being equally distributed on both sides of the NDI2OD moiety [as for the case of RR-P(NDI2OD-T2)]. The different stabilities in the UDFT solutions of the charged state, as well as the asymmetric distribution of the $\mathrm{SOMO}_{\beta}$ and spin density, are the only molecular-based features (i.e., at the single chain level) differentiating the RR- from the RI-P(NDI2OD-T2), and we believe that they might be at the origin of the different EPR signals. The asymmetric spin density distribution of the RI polymer, together with a more distorted chain structure (Figure 7), can result, at the macroscopic level, in a larger amount of paramagnetic species (i.e., charge density) present with respect to the RR one. The distorted chain structure of RI-P(NDI2OD-T2) induces a higher structural and energetic disorder, favoring a deeper percolation of the dopant molecules within the film, thus leading to higher doping level ${ }^{67}$ and polaron density than the RR-polymer. In this way, the combination of an extended $\pi$-conjugated system and the presence of a meta substitution in the chain both induce a different molecular structure, energetic disorder, and spatial 
localization of the polaron spin density with respect to the para substitution, possibly resulting in different EPR spectra.

Vibrational Spectroscopy Characterization: Experiments Versus Theory. As reported by Fazzi et al., ${ }^{68}$ RAIRS combined with quantum-chemical calculations is a powerful tool to investigate the vibrational, structural, and molecular orientation properties of polymer chains with respect to a refractive substrate. For the case of RR-P(NDI2OD-T2), we demonstrated the effectiveness of using a combined experimental/theoretical (i.e., RAIRS/DFT) approach, ${ }^{68}$ being able to derive the structure and orientations of RR-P(NDI2OD-T2) chains with respect to a gold substrate. The methodology required the assignment of specific IR-active normal modes and their transition dipole moment orientations (acting as vibrational/structural fingerprints), together with the selection rules governing the RAIRS band activities. As previously reported, ${ }^{68}$ the IR and RAIRS bands used for the vibrational and structural assignment of RR-P(NDI2OD-T2) are as follows:

- band I $\left(\sim 1720 \mathrm{~cm}^{-1}\right)$, that is, the IR-active $\mathrm{C}=\mathrm{O}$ symmetric stretching localized on the NDI2OD unit and polarized perpendicular to the polymer chain, namely, along the long axis of the NDI2OD plane;

- band II $\left(\sim 1680 \mathrm{~cm}^{-1}\right)$, that is, the IR-active $\mathrm{C}=\mathrm{O}$ antisymmetric stretching localized on the NDI2OD unit and polarized parallel to the polymer chain, namely, along the short axis of the NDI2OD plane;

On the basis of these assignments, the analysis of RAIRS spectra revealed that the polymer chains of a spin-coated RR$\mathrm{P}(\mathrm{NDI} 2 \mathrm{OD}-\mathrm{T} 2)$ film run parallel to the substrate, featuring the T2 units parallel to it and the NDI2OD units tilted by an angle of $42^{\circ} .68$

Here, we adopted a similar approach to get insights for both RR- and RI-P(NDI2OD-T2) into the doping process and the polymer/doping structure. Figure 8 shows the RAIRS spectra of RR and RI species in their pristine (undoped) state (cyan line), after $3 \mathrm{~min}$ (purple line) and $15 \mathrm{~h}$ of doping time with TDAE (green line) and doped with N-DMBI (blue line). In Figure 8, we also report the computed IR spectra of the neutral and charged species for both RR and RI cases (see also Figures S9 and S10). ${ }^{69}$ The RAIRS spectrum of pristine RR $\mathrm{P}$ (NDI2OD-T2) (Figure 8, left side) reproduces the spectral shape reported previously for spin-coated P(NDI2OD-T2) films. Accordingly, the intensity ratio of bands I and II ( $I_{\text {band I }} /$ $\left.I_{\text {band_II }}\right)$ indicates that the polymer chains are parallel to the substrate, with the NDI2OD units tilted by $42^{\circ}$ and the T2 units parallel with respect to the substrate. This is in agreement with a preferential face-on chain orientation observed by GIWAXS. The RAIRS of pristine RI-P(NDI2OD-T2) (Figure 8 , right side) is similar to the that of the $R R$ case, however showing a $I_{\text {band_I }} / I_{\text {band_II }}$ slightly higher than the RR case. This would suggest that the polymer chains (on average) are pointing slightly out of the substrate, being tilted or more distorted than those of RR. According to DFT structural calculations, because of the meta substitution, RI chains do show a more distorted structure than the RR ones, again consistent with the GIWAXS data reported in the previous section.

Upon doping, two additional RAIRS bands appear in the $1700-1600 \mathrm{~cm}^{-1}$ region (bands III and IV). Comparison of the DFT-computed IR spectra of the neutral and charged species (Figure 8, red and black lines) reveals that such bands are the result of the polymer chain doping process. In particular, band III and band IV, assigned for the first time here by DFT calculations (Figure 8), represent the IR-active $\mathrm{C}=\mathrm{O}$ symmetric and antisymmetric stretching oscillations of charged species (green arrows in Figure 8), respectively, as localized prevalently on one monomer unit of the chain. In detail, DFT calculations reveal that the normal modes related to bands III and IV are localized on the unit over which the polaron mainly relaxes, as visible in Figure 8 from the comparison between the sketches of the normal modes and the spin density maps. Bands III and IV are, consequently, the IR vibrational fingerprints of the $\mathrm{P}(\mathrm{NDI} 2 \mathrm{OD}-\mathrm{T} 2)$ polaron. They represent the IR-active $\mathrm{C}=\mathrm{O}$ symmetric and antisymmetric stretching modes, as bands I and II do, but their transition energies are red-shifted with respect to bands I and II. The energy shift can be explained by the removal of degeneracy, as induced by the break in the translational symmetry of the polymer because of polaron relaxations.

Having clarified the assignment of the bands, we can interpret the RAIRS spectra. At first, we can observe that doping affects the RAIRS spectra (Figure 8), suggesting different orientations of the polymer chains with respect to the substrate and, eventually, different polymer/dopant morphologies (as also observed by GIWAXS). For both the RR- and RI-P(NDI2OD-T2) polymers, doping with TDAE induces the appearance of band III as registered after $3 \mathrm{~min}$ of exposure to the dopant, whose RAIRS intensity increases further as recorded at $15 \mathrm{~h}$ of doping. For RI-P(NDI2OD-T2), the RAIRS intensity of band III is higher than that of the RR polymer after $15 \mathrm{~h}$ of doping and also band IV is further enhanced. According to the DFT band assignments, the RAIRS spectra reveal (i) the presence of a localized charge on the polymer chains and (ii) RI-P(NDI2OD-T2) chains being more tilted than the RR-P(NDI2OD-T2) ones, also featuring the NDI2OD units oriented more perpendicular to the substrate than the RR polymer. Moreover, the enhanced RAIRS intensity of the polaron band III of RI-P(NDI2ODT2) might suggest not only a more tilted orientation of the NDI2OD units but also a higher charge density than the RR species. We can assume that $I_{\text {band_I }} / I_{\text {band_II }}$ is representative for the backbone structural reorientation while $I_{\text {band_III }} / I_{\text {band_II }}$ for the polaron formation. At $15 \mathrm{~h}$ of doping, the $I_{\text {band I I }}^{-} / I_{\text {band }}$ II the same $(\sim 1)$ for both polymers. Assuming the polymer chain reorientation effects and the dopant diffusion processes as completed, the intensity ratio $I_{\text {band_III }} / I_{\text {band II }}$ at $15 \mathrm{~h}$ should correlate with the doping level (or charge density) of the polymer chains. The $I_{\text {band III }} / I_{\text {band II }}$ for RR- and RI$\mathrm{P}(\mathrm{NDI} 2 \mathrm{OD}-\mathrm{T} 2)$ at $15 \mathrm{~h}$, calculated from a Lorentzian deconvolution of the areas, is 1.3 and 3.9, respectively, thus $\sim 3 \times$ larger for the RI polymer. This result could be related to a higher doping level for RI- with respect to RR-P(NDI2ODT2). Similarly, a factor of 2 is present in the EPR spectral line width values (Figure 5), namely, 0.30 and $0.15 \mathrm{mT}$ for the RR and RI polymers, respectively, thus leading to a higher doping level for the latter. Considering our above assumptions valid, and accounting for the intrinsic error in decoupling the structural and doping contributions in the RAIRS signals, we could suggest that also from a quantitative analysis of the RAIRS intensities, RI-P(NDI2OD-T2) can be doped more efficiently $(\sim 3 \times)$ than RR-P(NDI2OD-T2), further supporting the EPR findings. Further in-depth and systematic investigations in this direction are required to better analyze the differences in the RAIRS spectra for various doping agents/ 
levels and film morphologies. Nevertheless, for the first time, we report here the effects of the doping process of $\mathrm{P}(\mathrm{NDI} 2 \mathrm{OD}-\mathrm{T} 2)$ polymer on the corresponding RAIRS spectra.

\section{CONCLUSIONS}

In conclusion, we investigated the impact of polymer backbone regiochemistry on the conductivity, charge density, and polaronic structure for $\mathrm{n}$-doped RR and RI donor-acceptor $\mathrm{P}$ (NDI2OD-T2)s. Interestingly, we found that the maximum electrical conductivity of doped RI-P(NDI2OD-T2) is statistically larger than that of RR-P(NDI2OD-T2), despite the considerably lower charge carrier mobility and the far less textured film microstructure of the former polymer. EPR measurements indicate that doped RI-P(NDI2OD-T2) possesses a significantly larger amount of paramagnetic species compared to the doped RR counterpart and thus can support a greater electron density as measured experimentally from combined conductivity/mobility data. This phenomenon arises from a different molecular chain structure, polaron structure, and spin density distribution in the RI polymer backbone, as suggested by DFT calculations. All of these data are in striking contrast to homopolymers such as P3HT and other $\pi$ conjugated polymers, where regioirregularity leads to a lower doping level, reduced charge carrier mobility, and thus far lower electrical conductivity. We attributed this to an increased tolerance of $\mathrm{P}$ (NDI2OD-T2) backbone to disorder. ${ }^{70}$ The RI structure in, for example, P3HT greatly impacts the planarization of the backbone because of steric constraints, which lock the undoped/doped polymer chains in severely twisted conformations. This prevents the P3HT chains from aggregating/crystallizing, reduces the conjugation length, and dramatically affects the energetic structure of the RI-P3HT films. In contrast, the mixed 2,6- and 2,7- NDI-T2 linkages in the RI-P(NDI2OD-T2) do not affect the intrachain steric demand of the backbone, yielding RI-P(NDI2OD-T2) with a similar conformational structure and LUMO energy as its RR counterpart. In comparison to homopolymers such as P3HT, negative polarons in $\mathrm{P}(\mathrm{NDI} 2 \mathrm{OD}-\mathrm{T} 2)$ are prevalently localized over mostly one repeating unit, as confirmed here by DFT computations and the comparison between theoretical and experimental IR/RAIRS spectra, thus providing a higher baseline for charge-transport tolerance to disorder regardless of the film microstructure.

\section{ASSOCIATED CONTENT}

\section{S Supporting Information}

The Supporting Information is available free of charge on the ACS Publications website at DOI: 10.1021/acs.chemmater.9b00558.

Additional characterization data, such as NMR, OFETs, UV-vis, EPR, GIWAXS, computed (DFT) IR spectra for oligomer $n_{5} \mathrm{RR}$ and RI (both neutral and charged states), together with the computed IR spectra of TDAE and N-DMBI anions, and DFT-optimized geometries for oligomer $n_{1}$ and $n_{5}$, considering both $\mathrm{RR}$ and $\mathrm{RI}$ substitutions (PDF)

\section{AUTHOR INFORMATION}

\section{Corresponding Authors}

*E-mail: dfazzi@uni-koeln.de (D.F.).

*E-mail: afacchetti@flexterracorp.com (A.F.).
*E-mail: simone.fabiano@liu.se (S.F.).

ORCID

Suhao Wang: 0000-0002-6295-7639

Yuttapoom Puttisong: 0000-0002-9690-6231

Mohammad J. Jafari: 0000-0003-3899-4891

Jens W. Andreasen: 0000-0002-3145-0229

Simone Fabiano: 0000-0001-7016-6514

\section{Author Contributions}

The manuscript was written through contributions from all authors. All authors have given approval to the final version of the manuscript.

\section{Notes}

The authors declare no competing financial interest.

\section{ACKNOWLEDGMENTS}

The authors acknowledge the support from the Knut and Alice Wallenberg foundation, the Swedish Foundation for Strategic Research. S.F. gratefully acknowledges funding by VINNOVA (2015-04859), the Swedish Research Council (2016-03979), the Advanced Functional Materials Center at Linköping University (2009-00971), and ÅForsk (18-313). A.F. thanks AFOSR (FA9550-18-1-0320). D.F. acknowledges the Deutsche Forschungsgemeinschaft (DFG) for a Principal Investigator grant (FA 1502/1-1 "Molecular Understanding of Thermo-Electric Properties in Organic Polymers"). J.W.A. gratefully acknowledges funding by the European Research Council (ERC) (681881).

\section{REFERENCES}

(1) Walzer, K.; Maennig, B.; Pfeiffer, M.; Leo, K. Highly Efficient Organic Devices Based on Electrically Doped Transport Layers. Chem. Rev. 2007, 107, 1233-1271.

(2) Kroon, R.; Mengistie, D. A.; Kiefer, D.; Hynynen, J.; Ryan, J. D.; Yu, L.; Müller, C. Thermoelectric plastics: from design to synthesis, processing and structure-property relationships. Chem. Soc. Rev. 2016, $45,6147-6164$.

(3) Kiefer, D.; Yu, L.; Fransson, E.; Gómez, A.; Primetzhofer, D.; Amassian, A.; Campoy-Quiles, M.; Müller, C. A Solution-Doped Polymer Semiconductor:Insulator Blend for Thermoelectrics. Adv. Sci. 2017, 4, 1600203.

(4) Yim, K.-H.; Whiting, G. L.; Murphy, C. E.; Halls, J. J. M.; Burroughes, J. H.; Friend, R. H.; Kim, J.-S. Controlling Electrical Properties of Conjugated Polymers via a Solution-Based p-Type Doping. Adv. Mater. 2008, 20, 3319-3324.

(5) Glaudell, A. M.; Cochran, J. E.; Patel, S. N.; Chabinyc, M. L. Impact of the Doping Method on Conductivity and Thermopower in Semiconducting Polythiophenes. Adv. Energy Mater. 2015, 5, 1401072.

(6) Zuo, G.; Abdalla, H.; Kemerink, M. Impact of doping on the density of states and the mobility in organic semiconductors. Phys. Rev. B 2016, 93, 235203.

(7) Guo, S.; Kim, S. B.; Mohapatra, S. K.; Qi, Y.; Sajoto, T.; Kahn, A.; Marder, S. R.; Barlow, S. n-Doping of Organic Electronic Materials using Air-Stable Organometallics. Adv. Mater. 2012, 24, 699-703.

(8) Kang, K.; Watanabe, S.; Broch, K.; Sepe, A.; Brown, A.; Nasrallah, I.; Nikolka, M.; Fei, Z.; Heeney, M.; Matsumoto, D.; Marumoto, K.; Tanaka, H.; Kuroda, S.-i.; Sirringhaus, H. 2D coherent charge transport in highly ordered conducting polymers doped by solid state diffusion. Nat. Mater. 2016, 15, 896-902.

(9) Patel, S. N.; Glaudell, A. M.; Peterson, K. A.; Thomas, E. M.; O'Hara, K. A.; Lim, E.; Chabinyc, M. L. Morphology controls the thermoelectric power factor of a doped semiconducting polymer. Sci. Adv. 2017, 3, No. e1700434.

(10) Kao, C. Y.; Lee, B.; Wielunski, L. S.; Heeney, M.; McCulloch, I.; Garfunkel, E.; Feldman, L. C.; Podzorov, V. Doping of Conjugated 
Polythiophenes with Alkyl Silanes. Adv. Funct. Mater. 2009, 19, 19061911.

(11) Chew, A. R.; Ghosh, R.; Shang, Z.; Spano, F. C.; Salleo, A. Sequential Doping Reveals the Importance of Amorphous Chain Rigidity in Charge Transport of Semi-Crystalline Polymers. J. Phys. Chem. Lett. 2017, 8, 4974-4980.

(12) Jacobs, I. E.; Aasen, E. W.; Oliveira, J. L.; Fonseca, T. N.; Roehling, J. D.; Li, J.; Zhang, G.; Augustine, M. P.; Mascal, M.; Moulé, A. J. Comparison of solution-mixed and sequentially processed P3HT:F4TCNQ films: effect of doping-induced aggregation on film morphology. J. Mater. Chem. C 2016, 4, 3454-3466.

(13) Zuo, G.; Li, Z.; Wang, E.; Kemerink, M. High Seebeck Coefficient and Power Factor in n-Type Organic Thermoelectrics. Adv. Electron. Mater. 2018, 4, 1700501.

(14) Mityashin, A.; Olivier, Y.; Van Regemorter, T.; Rolin, C.; Verlaak, S.; Martinelli, N. G.; Beljonne, D.; Cornil, J.; Genoe, J.; Heremans, P. Unraveling the Mechanism of Molecular Doping in Organic Semiconductors. Adv. Mater. 2012, 24, 1535-1539.

(15) Zhang, Y.; Zhou, H.; Seifter, J.; Ying, L.; Mikhailovsky, A.; Heeger, A. J.; Bazan, G. C.; Nguyen, T.-Q. Molecular Doping Enhances Photoconductivity in Polymer Bulk Heterojunction Solar Cells. Adv. Mater. 2013, 25, 7038-7044.

(16) Zhou, Y.; Fuentes-Hernandez, C.; Shim, J.; Meyer, J.; Giordano, A. J.; Li, H.; Winget, P.; Papadopoulos, T.; Cheun, H.; Kim, J.; Fenoll, M.; Dindar, A.; Haske, W.; Najafabadi, E.; Khan, T. M.; Sojoudi, H.; Barlow, S.; Graham, S.; Bredas, J.-L.; Marder, S. R.; Kahn, A.; Kippelen, B. A Universal Method to Produce Low-Work Function Electrodes for Organic Electronics. Science 2012, 336, 327332.

(17) Zalar, P.; Henson, Z. B.; Welch, G. C.; Bazan, G. C.; Nguyen, T.-Q. Color Tuning in Polymer Light-Emitting Diodes with Lewis Acids. Angew. Chem., Int. Ed. 2012, 51, 7495-7498.

(18) Tang, C. G.; Ang, M. C. Y.; Choo, K.-K.; Keerthi, V.; Tan, J.-K.; Syafiqah, M. N.; Kugler, T.; Burroughes, J. H.; Png, R.-Q.; Chua, L.L.; Ho, P. K. H. Doped polymer semiconductors with ultrahigh and ultralow work functions for ohmic contacts. Nature 2016, 539, 536540.

(19) Lu, G.; Blakesley, J.; Himmelberger, S.; Pingel, P.; Frisch, J.; Lieberwirth, I.; Salzmann, I.; Oehzelt, M.; Di Pietro, R.; Salleo, A.; Koch, N.; Neher, D. Moderate doping leads to high performance of semiconductor/insulator polymer blend transistors. Nat. Commun. 2013, 4, 1588.

(20) Khim, D.; Baeg, K.-J.; Caironi, M.; Liu, C.; Xu, Y.; Kim, D.-Y.; Noh, Y.-Y. Control of Ambipolar and Unipolar Transport in Organic Transistors by Selective Inkjet-Printed Chemical Doping for High Performance Complementary Circuits. Adv. Funct. Mater. 2014, 24, 6252-6261.

(21) Li, H.; DeCoster, M. E.; Ireland, R. M.; Song, J.; Hopkins, P. E.; Katz, H. E. Modification of the Poly(bisdodecylquaterthiophene) Structure for High and Predominantly Nonionic Conductivity with Matched Dopants. J. Am. Chem. Soc. 2017, 139, 11149-11157.

(22) Liang, Y.; Chen, Z.; Jing, Y.; Rong, Y.; Facchetti, A.; Yao, Y. Heavily n-Dopable $\pi$-Conjugated Redox Polymers with Ultrafast Energy Storage Capability. J. Am. Chem. Soc. 2015, 137, 4956-4959.

(23) Bubnova, O.; Crispin, X. Towards polymer-based organic thermoelectric generators. Energy Environ. Sci. 2012, 5, 9345-9362.

(24) Karpov, Y.; Erdmann, T.; Raguzin, I.; Al-Hussein, M.; Binner, M.; Lappan, U.; Stamm, M.; Gerasimov, K. L.; Beryozkina, T.; Bakulev, V.; Anokhin, D. V.; Ivanov, D. A.; Günther, F.; Gemming, S.; Seifert, G.; Voit, B.; Di Pietro, R.; Kiriy, A. High Conductivity in Molecularly p-Doped Diketopyrrolopyrrole-Based Polymer: The Impact of a High Dopant Strength and Good Structural Order. Adv. Mater. 2016, 28, 6003-6010.

(25) Bubnova, O.; Khan, Z. U.; Wang, H.; Braun, S.; Evans, D. R.; Fabretto, M.; Hojati-Talemi, P.; Dagnelund, D.; Arlin, J.-B.; Geerts, Y. H.; Desbief, S.; Breiby, D. W.; Andreasen, J. W.; Lazzaroni, R.; Chen, W. M.; Zozoulenko, I.; Fahlman, M.; Murphy, P. J.; Berggren, M.; Crispin, X. Semi-metallic polymers. Nat. Mater. 2014, 13, 190-194.
(26) Shi, K.; Zhang, F.; Di, C.-A.; Yan, T.-W.; Zou, Y.; Zhou, X.; Zhu, D.; Wang, J.-Y.; Pei, J. Toward High Performance n-Type Thermoelectric Materials by Rational Modification of BDPPV Backbones. J. Am. Chem. Soc. 2015, 137, 6979-6982.

(27) Zhao, X.; Madan, D.; Cheng, Y.; Zhou, J.; Li, H.; Thon, S. M.; Bragg, A. E.; DeCoster, M. E.; Hopkins, P. E.; Katz, H. E. High Conductivity and Electron-Transfer Validation in an n-Type FluorideAnion-Doped Polymer for Thermoelectrics in Air. Adv. Mater. 2017, 29, 1606928.

(28) Schlitz, R. A.; Brunetti, F. G.; Glaudell, A. M.; Miller, P. L.; Brady, M. A.; Takacs, C. J.; Hawker, C. J.; Chabinyc, M. L. SolubilityLimited Extrinsic n-Type Doping of a High Electron Mobility Polymer for Thermoelectric Applications. Adv. Mater. 2014, 26, 2825-2830.

(29) Kiefer, D.; Giovannitti, A.; Sun, H.; Biskup, T.; Hofmann, A.; Koopmans, M.; Cendra, C.; Weber, S.; Anton Koster, L. J.; Olsson, E.; Rivnay, J.; Fabiano, S.; McCulloch, I.; Müller, C. Enhanced n-Doping Efficiency of a Naphthalenediimide-Based Copolymer through Polar Side Chains for Organic Thermoelectrics. ACS Energy Lett. 2018, 3, $278-285$.

(30) Liu, J.; Qiu, L.; Alessandri, R.; Qiu, X.; Portale, G.; Dong, J.; Talsma, W.; Ye, G.; Sengrian, A. A.; Souza, P. C. T.; Loi, M. A.; Chiechi, R. C.; Marrink, S. J.; Hummelen, J. C.; Koster, L. J. A. Enhancing Molecular n-Type Doping of Donor-Acceptor Copolymers by Tailoring Side Chains. Adv. Mater. 2018, 30, 1704630.

(31) Shin, Y.; Massetti, M.; Komber, H.; Biskup, T.; Nava, D.; Lanzani, G.; Caironi, M.; Sommer, M. Improving Miscibility of a Naphthalene Diimide-Bithiophene Copolymer with n-Type Dopants through the Incorporation of "Kinked" Monomers. Adv. Electron. Mater. 2018, 4, 1700581.

(32) Yan, H.; Chen, Z.; Zheng, Y.; Newman, C.; Quinn, J. R.; Dötz, F.; Kastler, M.; Facchetti, A. A high-mobility electron-transporting polymer for printed transistors. Nature 2009, 457, 679-686.

(33) Wang, S.; Sun, H.; Ail, U.; Vagin, M.; Persson, P. O. Å.; Andreasen, J. W.; Thiel, W.; Berggren, M.; Crispin, X.; Fazzi, D.; Fabiano, S. Thermoelectric Properties of Solution-Processed n-Doped Ladder-Type Conducting Polymers. Adv. Mater. 2016, 28, 1076410771.

(34) Naab, B. D.; Gu, X.; Kurosawa, T.; To, J. W. F.; Salleo, A.; Bao, Z. Role of Polymer Structure on the Conductivity of N-Doped Polymers. Adv. Electron. Mater. 2016, 2, 1600004.

(35) de la Peña, A.; Arrechea-Marcos, I.; Mancheño, M. J.; Ruiz Delgado, M. C.; López Navarrete, J. T.; Segura, J. L.; Ponce Ortiz, R. Tuning of the Electronic Levels of Oligothiophene-Naphthalimide Assemblies by Chemical Modification. Chem. Eur. J. 2016, 22, 13643-13652.

(36) Riaño Carnerero, A.; López Espejo, G.; Mancheño Real, M. J.; Eckstein, B.; González-Cano, R. C.; Melkonyan, F. S.; Facchetti, A.; Marks, T. J.; Casado, J.; López Navarrete, J. T.; Segura, J. L.; Ponce Ortiz, R. Even and odd oligothiophene-bridged bis-naphthalimides for n-type and ambipolar organic field effect transistors. J. Mater. Chem. C 2017, 5, 9439-9450.

(37) Zhang, L.; Rose, B. D.; Liu, Y.; Nahid, M. M.; Gann, E.; Ly, J.; Zhao, W.; Rosa, S. J.; Russell, T. P.; Facchetti, A.; McNeill, C. R.; Brédas, J.-L.; Briseno, A. L. Efficient Naphthalenediimide-Based Hole Semiconducting Polymer with Vinylene Linkers between Donor and Acceptor Units. Chem. Mater. 2016, 28, 8580-8590.

(38) Ly, J. T.; Burnett, E. K.; Thomas, S.; Aljarb, A.; Liu, Y.; Park, S.; Rosa, S.; Yi, Y.; Lee, H.; Emrick, T.; Russell, T. P.; Brédas, J.-L.; Briseno, A. L. Efficient Electron Mobility in an All-Acceptor Napthalenediimide-Bithiazole Polymer Semiconductor with Large Backbone Torsion. ACS Appl. Mater. Interfaces 2018, 10, 4007040077.

(39) Wang, S.; Sun, H.; Erdmann, T.; Wang, G.; Fazzi, D.; Lappan, U.; Puttisong, Y.; Chen, Z.; Berggren, M.; Crispin, X.; Kiriy, A.; Voit, B.; Marks, T. J.; Fabiano, S.; Facchetti, A. A Chemically Doped Naphthalenediimide-Bithiazole Polymer for n-Type Organic Thermoelectrics. Adv. Mater. 2018, 30, 1801898. 
(40) Hynynen, J.; Kiefer, D.; Yu, L.; Kroon, R.; Munir, R.; Amassian, A.; Kemerink, M.; Müller, C. Enhanced Electrical Conductivity of Molecularly p-Doped Poly(3-hexylthiophene) through Understanding the Correlation with Solid-State Order. Macromolecules 2017, 50, $8140-8148$.

(41) Apitz, D.; Bertram, R. P.; Benter, N.; Hieringer, W.; Andreasen, J. W.; Nielsen, M. M.; Johansen, P. M.; Buse, K. Investigation of chromophore-chromophore interaction by electro-optic measurements, linear dichroism, x-ray scattering, and density-functional calculations. Phys. Rev. E: Stat., Nonlinear, Soft Matter Phys. 2005, $72,036610$.

(42) Breiby, D. W.; Bunk, O.; Andreasen, J. W.; Lemke, H. T.; Nielsen, M. M. Simulating X-ray diffraction of textured films. J. Appl. Crystallogr. 2008, 41, 262-271.

(43) Frisch, M. J.; Trucks, G. W.; Schlegel, H. B.; Scuseria, G. E.; Robb, M. A.; Cheeseman, J. R.; Scalmani, G.; Barone, V.; Mennucci, B.; Petersson, G. A.; Nakatsuji, H.; Caricato, M.; Li, X.; Hratchian, H. P.; Izmaylov, A. F.; Bloino, J.; Zheng, G.; Sonnenberg, J. L.; Hada, M.; Ehara, M.; Toyota, K.; Fukuda, R.; Hasegawa, J.; Ishida, M.; Nakajima, T.; Honda, Y.; Kitao, O.; Nakai, H.; Vreven, T.; Montgomery, J. A., Jr.; Peralta, J. E.; Ogliaro, F. E. ß.; Bearpark, M. J.; Heyd, J.; Brothers, E. N.; Kudin, K. N.; Staroverov, V. N.; Kobayashi, R.; Normand, J.; Raghavachari, K.; Rendell, A. P.; Burant, J. C.; Iyengar, S. S.; Tomasi, J.; Cossi, M.; Rega, N.; Millam, N. J.; Klene, M.; Knox, J. E.; Cross, J. B.; Bakken, V.; Adamo, C.; Jaramillo, J.; Gomperts, R.; Stratmann, R. E.; Yazyev, O.; Austin, A. J.; Cammi, R.; Pomelli, C.; Ochterski, J. W.; Martin, R. L.; Morokuma, K.; Zakrzewski, V. G.; Voth, G. A.; Salvador, P.; Dannenberg, J. J.; Dapprich, S.; Daniels, A. D.; Farkas, É. Ä. É. n.; Foresman, J. B.; Ortiz, J. V.; Cioslowski, J.; Fox, D. J. Gaussian 09, Revision D.01; Gaussian, Inc.: Wallingford, CT, USA, 2009.

(44) Steyrleuthner, R.; Di Pietro, R.; Collins, B. A.; Polzer, F.; Himmelberger, S.; Schubert, M.; Chen, Z.; Zhang, S.; Salleo, A.; Ade, H.; Facchetti, A.; Neher, D. The Role of Regioregularity, Crystallinity, and Chain Orientation on Electron Transport in a High-Mobility nType Copolymer. J. Am. Chem. Soc. 2014, 136, 4245-4256.

(45) Wetzelaer, G.-J. A. H.; Kuik, M.; Olivier, Y.; Lemaur, V.; Cornil, J.; Fabiano, S.; Loi, M. A.; Blom, P. W. M. Asymmetric electron and hole transport in a high-mobility n-type conjugated polymer. Phys. Rev. B: Condens. Matter Mater. Phys. 2012, 86, 165203.

(46) Fazzi, D.; Caironi, M.; Castiglioni, C. Quantum-Chemical Insights into the Prediction of Charge Transport Parameters for a Naphthalenetetracarboxydiimide-Based Copolymer with Enhanced Electron Mobility. J. Am. Chem. Soc. 2011, 133, 19056-19059.

(47) Ko, S.; Hoke, E. T.; Pandey, L.; Hong, S.; Mondal, R.; Risko, C.; Yi, Y.; Noriega, R.; McGehee, M. D.; Brédas, J.-L.; Salleo, A.; Bao, Z. Controlled Conjugated Backbone Twisting for an Increased OpenCircuit Voltage while Having a High Short-Circuit Current in Poly(hexylthiophene) Derivatives. J. Am. Chem. Soc. 2012, 134, 5222-5232.

(48) Chen, Z.; Zheng, Y.; Yan, H.; Facchetti, A. Naphthalenedicarboximide- vs Perylenedicarboximide-Based Copolymers. Synthesis and Semiconducting Properties in Bottom-Gate N-Channel Organic Transistors. J. Am. Chem. Soc. 2009, 131, 8-9.

(49) Naab, B. D.; Guo, S.; Olthof, S.; Evans, E. G. B.; Wei, P.; Millhauser, G. L.; Kahn, A.; Barlow, S.; Marder, S. R.; Bao, Z. Mechanistic Study on the Solution-Phase n-Doping of 1,3-Dimethyl2-aryl-2,3-dihydro-1H-benzoimidazole Derivatives. J. Am. Chem. Soc. 2013, 135, 15018-15025.

(50) Naab, B. D.; Zhang, S.; Vandewal, K.; Salleo, A.; Barlow, S.; Marder, S. R.; Bao, Z. Effective Solution- and Vacuum-Processed nDoping by Dimers of Benzimidazoline Radicals. Adv. Mater. 2014, 26, 4268-4272.

(51) Gross, Y. M.; Trefz, D.; Tkachov, R.; Untilova, V.; Brinkmann, M.; Schulz, G. L.; Ludwigs, S. Tuning Aggregation by Regioregularity for High-Performance n-Type P(NDI2OD-T2) Donor-Acceptor Copolymers. Macromolecules 2017, 50, 5353-5366.

(52) Sirringhaus, H.; Brown, P. J.; Friend, R. H.; Nielsen, M. M.; Bechgaard, K.; Langeveld-Voss, B. M. W.; Spiering, A. J. H.; Janssen,
R. A. J.; Meijer, E. W.; Herwig, P.; de Leeuw, D. M. Two-dimensional charge transport in self-organized, high-mobility conjugated polymers. Nature 1999, 401, 685-688.

(53) Ying, L.; Hsu, B. B. Y.; Zhan, H.; Welch, G. C.; Zalar, P.; Perez, L. A.; Kramer, E. J.; Nguyen, T.-Q.; Heeger, A. J.; Wong, W.-Y.; Bazan, G. C. Regioregular Pyridal[2,1,3]thiadiazole $\pi$-Conjugated Copolymers. J. Am. Chem. Soc. 2011, 133, 18538-18541.

(54) Qin, T.; Zajaczkowski, W.; Pisula, W.; Baumgarten, M.; Chen, M.; Gao, M.; Wilson, G.; Easton, C. D.; Müllen, K.; Watkins, S. E. Tailored Donor-Acceptor Polymers with an A-D1-A-D2 Structure: Controlling Intermolecular Interactions to Enable Enhanced Polymer Photovoltaic Devices. J. Am. Chem. Soc. 2014, 136, 6049-6055.

(55) Steyrleuthner, R.; Schubert, M.; Howard, I.; Klaumünzer, B.; Schilling, K.; Chen, Z.; Saalfrank, P.; Laquai, F.; Facchetti, A.; Neher, D. Aggregation in a High-Mobility n-Type Low-Bandgap Copolymer with Implications on Semicrystalline Morphology. J. Am. Chem. Soc. 2012, 134, 18303-18317.

(56) Wiberg, N. Tetraaminoethylenes as Strong Electron Donors. Angew. Chem., Int. Ed. 1968, 7, 766-779.

(57) Mohr, P. J.; Taylor, B. N. CODATA recommended values of the fundamental physical constants: 2002. Rev. Mod. Phys. 2005, 77, $1-107$.

(58) Gao, J.; Niles, E. T.; Grey, J. K. Aggregates Promote Efficient Charge Transfer Doping of Poly(3-hexylthiophene). J. Phys. Chem. Lett. 2013, 4, 2953-2957.

(59) Onoda, M.; Manda, Y.; Morita, S.; Yoshino, K. In Situ Electron Spin Resonance Measurements of Electrochemically Doped n-Type Polythiophene. J. Phys. Soc. Jpn. 1990, 59, 213-217.

(60) Milián-Medina, B.; Wykes, M.; Chen, Z.; Facchetti, A.; Gierschner, J. Regio(ir)regular naphthalenediimide- and perylenediimide-bithiophene copolymers: how MO localization controls the bandgap. J. Mater. Chem. C 2016, 4, 9405-9410.

(61) Neese, F. Definition of corresponding orbitals and the diradical character in broken symmetry DFT calculations on spin coupled systems. J. Phys. Chem. Solids 2004, 65, 781-785.

(62) Neese, F. Prediction of molecular properties and molecular spectroscopy with density functional theory: From fundamental theory to exchange-coupling. Coord. Chem. Rev. 2009, 253, 526-563.

(63) Canola, S.; Casado, J.; Negri, F. The double exciton state of conjugated chromophores with strong diradical character: insights from TDDFT calculations. Phys. Chem. Chem. Phys. 2018, 20, 2422724238.

(64) Casado, J.; Ponce Ortiz, R.; López Navarrete, J. T. Quinoidal oligothiophenes: new properties behind an unconventional electronic structure. Chem. Soc. Rev. 2012, 41, 5672-5686.

(65) Fazzi, D.; Canesi, E. V.; Negri, F.; Bertarelli, C.; Castiglioni, C. Biradicaloid Character of Thiophene-Based Heterophenoquinones: The Role of Electron-Phonon Coupling. ChemPhysChem 2010, 11, 3685-3695.

(66) Ghosh, S.; Verma, P.; Cramer, C. J.; Gagliardi, L.; Truhlar, D. G. Combining Wave Function Methods with Density Functional Theory for Excited States. Chem. Rev. 2018, 118, 7249-7292.

(67) Tietze, M. L.; Benduhn, J.; Pahner, P.; Nell, B.; Schwarze, M.; Kleemann, H.; Krammer, M.; Zojer, K.; Vandewal, K.; Leo, K. Elementary steps in electrical doping of organic semiconductors. Nat. Commun. 2018, 9, 1182.

(68) Giussani, E.; Fazzi, D.; Brambilla, L.; Caironi, M.; Castiglioni, C. Molecular Level Investigation of the Film Structure of a High Electron Mobility Copolymer via Vibrational Spectroscopy. Macromolecules 2013, 46, 2658-2670.

(69) DFT IR spectra would represent the equivalent of an FT-IR experiment, i.e. simulating isotropic conditions, rather than RAIRS. RAIRS is a polarized technique following specific selection rules at the incidence plane between the incoming light and the refractive substrate, thus changing the spectral shape with respect to a transmittance FT-IR experiment. RAIRS selection rules are not accounted for in the DFT simulations, therefore the spectral shapes of the two cases differ. Nevertheless, a full spectroscopic assignment can 
be carried out because the vibrational transitions are not affected by the RAIRS selection rules.

(70) Wang, S.; Fabiano, S.; Himmelberger, S.; Puzinas, S.; Crispin, X.; Salleo, A.; Berggren, M. Experimental evidence that short-range intermolecular aggregation is sufficient for efficient charge transport in conjugated polymers. Proc. Natl. Acad. Sci. U.S.A. 2015, 112, 1059910604. 